\title{
Study on Adsorption Properties of Loess Calcareous Nodules to Heavy Metalions In Aqueous-solution
}

\section{Qi Li (D420778295@qq.com)}

Shaanxi Provincial Land Engineering Construction Group Co., Ltd

\section{Li Yanan}

Shaanxi Provincial Land Engineering Construction Group Co., Ltd

\section{Xiaoxiao Shu}

Shaanxi Provincial Land Engineering Construction Group Co., Ltd

\section{Research Article}

Keywords: loess calcareous nodules, heavy metal ions, single adsorption, adsorption rate

Posted Date: June 3rd, 2021

DOI: https://doi.org/10.21203/rs.3.rs-579189/v1

License: (c) (i) This work is licensed under a Creative Commons Attribution 4.0 International License.

Read Full License 


\section{Abstract}

Using calcareous calcareous tuberculosis as adsorbent and heavy metal ions $\left(\mathrm{Cu}^{2+}, \mathrm{Zn}^{2+}, \mathrm{Cd}^{2+}\right.$ and $\left.\mathrm{Pb}^{2+}\right)$ as adsorbents, different particle size, adsorption time, $\mathrm{pH}$, adsorbent dosage and initial concentration of heavy metals were studied by single heavy metal adsorption test. And the influence of temperature and other factors on the adsorption of heavy metal ions by calcareous nodules, and determine the optimal conditions for the adsorption of heavy metal ions by calcareous nodules. The results show that the adsorption rates of $\mathrm{Cu}^{2+}, \mathrm{Zn}^{2+}$ and $\mathrm{Pb}^{2+}$ decrease gradually with the increase of particle size, but have no obvious effect on $\mathrm{Cd}^{2+}$. With the increase of adsorption time, adsorbent dosage and temperature, the adsorption rates of $\mathrm{Cu}^{2+}, \mathrm{Zn}^{2+}, \mathrm{Cd}^{2+}$ and $\mathrm{Pb}^{2+}$ gradually increase. The adsorption rate of $\mathrm{Cu}^{2+}, \mathrm{Zn}^{2+}$ and $\mathrm{Cd}^{2+}$ decreased gradually with the increase of the initial concentration of heavy metal ions, while the adsorption rate of $\mathrm{Pb}^{2+}$ increased first and then decreased. With the increase of $\mathrm{pH}$, the adsorption rate of $\mathrm{Cd}^{2+}$ increased first and then increased slowly. The adsorption rates of $\mathrm{Cu}^{2+}, \mathrm{Zn}^{2+}$ and $\mathrm{Pb}^{2+}$ increased first and then decreased. The adsorption capacity of calcareous nodules to four heavy metal ions is in the order of $\mathrm{Pb}^{2+} \nabla \mathrm{Zn}^{2+} \rrbracket \mathrm{Cu}^{2+} \llbracket \mathrm{Cd}^{2+}$. When the particle size is $0.25 \mathrm{~mm}$, the adsorption time is $120 \mathrm{~min}$, and the dosage is $0.6 \mathrm{~g}$, the calcareous nodules are $\mathrm{Pb}^{2+}, \mathrm{Zn}^{2+}, \mathrm{Cu}^{2+}$. And $\mathrm{Cd}^{2+}$ can achieve better adsorption, and the adsorption rate can reach $83.33 \%, 77.78 \%, 73.81 \%$ and $81.93 \%$ of its maximum adsorption rate, respectively. The optimal adsorption $\mathrm{pH}$ of calcareous nodules to $\mathrm{Pb}^{2+}, \mathrm{Zn}^{2+}, \mathrm{Cu}^{2+}$ and $\mathrm{Cd}^{2+}$ was $7,6,5$ and 8 , respectively, and the optimal temperature was $50^{\circ} \mathrm{C}$.

\section{Introduction}

In recent years, with the rapid development of industrialization and urbanization, a large amount of wastewater containing heavy metal ions such as $\mathrm{Cu}^{2+}, \mathrm{Zn}^{2+}, \mathrm{Cd}^{2+}$, and $\mathrm{Pb}^{2+}$ has entered water ecosystems, and the situation of heavy metal pollution of water body has become increasingly serious(Zhang Z.et al., 2015).Heavy metals have the characteristics of strong toxicity, easy migration and difficult degradation, and will seriously damage human health after entering the water body. Therefore, how to purify water and metal ions has become a hot issue in the treatment of environmental pollution(Wang YY.et al., 2018). Water and metal pollution treatment is a long-term and arduous task, so the cost and environmental friendliness must be fully considered when selecting a treatment method. The adsorption method is more suitable for various low-concentration heavy metal pollution water bodies due to its advantages such as fast treatment rate, simple operation, and good environmental coordination (Zou J .et al., 2018; Li L I .et al., 2012). In the application of adsorption methods, commonly used adsorbents are activated carbon, chitosan, resin, zeolite, sepiolite, and clay minerals such as kaolinite, vermiculite and montmorillonite (Liu J .et al., 2018). Studies have shown that vermiculite has a strong adsorption capacity for $\mathrm{Pb}^{2+}, \mathrm{Cd}^{2+}$, and $\mathrm{Zn}^{2+}$ in water(Hu H et al., 2012;Zehua $\mathrm{J} \mathrm{I,2015),} \mathrm{and} \mathrm{sepiolite} \mathrm{has}$ a good adsorption effect for $\mathrm{Ni}^{2+}, \mathrm{Cd}^{2+}, \mathrm{Zn}^{2+}$, and $\mathrm{Cu}^{2+}$ in water (Sheikhhosseini $\mathrm{A}$.et al., 2013). Studies on the adsorption of heavy metal ions by clay minerals have shown that illite, kaolinite and 
montmorillonite have good adsorption effects on $\mathrm{Cu}^{2+}, \mathrm{Zn}^{2+}, \mathrm{Cr}^{3+}, \mathrm{Cd}^{2+}$ and $\mathrm{Pb}^{2+}$ in water ( $\mathrm{He} \mathrm{H} \mathrm{P} \mathrm{.et}$ al., 2001).

Loess calcareous nodules, also known as "material ginger stone". It is a soil aggregate of different sizes and shapes under the action of leaching, sedimentation, alteration, and human activities under the conditions of alternating wet and dry conditions and freeze-thaw conditions in the soil on the Loess Plateau(Gong T .et al., 2016). Calcareous nodules are widely distributed in the heavily eroded Loess Plateau, and are mainly composed of primary minerals such as calcite, quartz and feldspar, and layered silicate minerals such as kaolinite, montmorillonite and illite. Among them, illite and montmorillonite have characteristics of huge specific surface area, high activity, and porosity, and can effectively adsorb heavy metal ions in water(Teng Zhihong .et al., 1990). Previous studies on loess calcareous nodules have mainly focused on its origin, distribution, structure, and mechanical properties (Wang Shouyu .et al., 2017;Gong Tiexiong .et al., 2017;Gong T .et al., 2016;Li Chang'an .et al., 1995), but there are few reports on the adsorption characteristics of heavy metal ions on the surface of calcareous nodules. As a natural mineral aggregate, calcareous nodules have the advantages of wide sources, low prices, no secondary pollution when added to water, and easy promotion. In addition, through the method of "treating waste by waste", it not only improves the soil body, but also reduces the heavy metal ions in the water body. It is a material with good environmental coordination. For this reason, this paper studies the adsorption characteristics of loess calcareous nodules on water and heavy metal ions, which can provide a theoretical basis for the application of this adsorbent in removing heavy metals from polluted water.

\section{Materials And Methods}

\subsection{Materials}

Test loess calcareous nodules were collected from forest land in Tongchuan City, Shaanxi Province, China $\left(34^{\circ} 99^{\prime} \mathrm{N} ; 108^{\circ} 92^{\prime} \mathrm{E}\right)$. Calcium nodules of similar size and shape are mainly collected in the surface soil of 0-20 cm and air-dried for later use. The reagents such as $\mathrm{Cu}\left(\mathrm{NO}_{3}\right)_{2}, \mathrm{Zn}\left(\mathrm{NO}_{3}\right)_{2}, \mathrm{Cd}\left(\mathrm{NO}_{3}\right)_{2}, \mathrm{~Pb}$ $\left(\mathrm{NO}_{3}\right) 2, \mathrm{HNO}_{3}$ and $\mathrm{NaOH}$ are all excellent pure. The test water is distilled water, which is used to prepare standard solutions of different heavy metal concentrations.

\subsection{Methods}

\section{Scanning electron microscope and microwave digestion test of calcareous tuberculosis}

The calcareous tuberculosis powder was prepared into a suspension, and the suspension was evenly coated on a copper table with a pipette. After being naturally air-dried, it was scanned under a highresolution scanning electron microscope. The chemical composition of calcareous nodules was extracted by aqua regia-hydrofluoric acid microwave digestion method, and the extract was measured by inductively coupled d plasma mass spectrometer (ICP-MS)(Yang L G .et al., 2019).

\section{Test for Calcium Nodule Adsorption to Heavy Metal lons}


A single heavy metal adsorption test was performed under different conditions using calcium nodules as an adsorbent, and an aqueous solution containing heavy metal ions such as $\mathrm{Cu}^{2+}, \mathrm{Zn}^{2+}, \mathrm{Cd}^{2+}$, and $\mathrm{Pb}^{2+}$ as the adsorption target.

The particle size test refers to taking $0.2 \mathrm{~g}$ of sieve calcium nodules through $1,0.5,0.25,0.18$, and 0.149 $\mathrm{mm}$, respectively. Then, add $50 \mathrm{ml}$ of $\mathrm{Cu}^{2+}, \mathrm{Zn}^{2+}, \mathrm{Cd}^{2+}$ and $\mathrm{Pb}^{2+}$ at a concentration of $30 \mathrm{mg} / \mathrm{L}$, shake at constant temperature $\left(25 \pm 1{ }^{\circ} \mathrm{C}\right)$ for 120 minutes, centrifuge the supernatant to determine the heavy metal ion content by ICP-MS.

The adsorption time test is to take $0.2 \mathrm{~g}$ of calcic nodules through $0.25 \mathrm{~mm}$ sieve, and add $50 \mathrm{ml}$ of $\mathrm{Cu}^{2+}$, $\mathrm{Zn}^{2+}, \mathrm{Cd}^{2+}$ and $\mathrm{Pb}^{2+}$ at a concentration of $30 \mathrm{mg} / \mathrm{L}$. Samples were taken at $1,3,5,15,30,60,90,120$ minutes of shaking time, and then the content of heavy metal ions in the supernatant was measured.

$\mathrm{pH}$ test: take $0.2 \mathrm{~g}$ of calcium nodules through a $0.25 \mathrm{~mm}$ sieve and add $30 \mathrm{mg} / \mathrm{L}$ of $50 \mathrm{mg}$ solution of $\mathrm{Cu}^{2+}, \mathrm{Zn}^{2+}, \mathrm{Cd}^{2+}$ and $\mathrm{Pb}^{2+}$ at $\mathrm{pH} 5,6,7,8$, and 9 respectively. The other test conditions are the same Diameter test.

Adsorbent dosage test: take $0.2,0.4,0.6,0.8$ and $1 \mathrm{~g}$ of calcium nodules through a $0.25 \mathrm{~mm}$ sieve, respectively, and add $50 \mathrm{mg}$ solutions of $\mathrm{Cu}^{2+}, \mathrm{Zn}^{2+}, \mathrm{Cd}^{2+}$ and $\mathrm{Pb}^{2+}$ at a concentration of $30 \mathrm{mg} / \mathrm{L}$, the other test conditions are the same as above .

Heavy metal initial concentration test: Take $0.2 \mathrm{~g}$ of $0.25 \mathrm{~mm}$ sieve calcareous nodules and add $50 \mathrm{ml}$ solutions of $\mathrm{Cu}^{2+}, \mathrm{Zn}^{2+}, \mathrm{Cd}^{2+}$ and $\mathrm{Pb}^{2+}$ at concentrations of $10,20,30,50$ and $100 \mathrm{mg} / \mathrm{L}$ respectively. The other test conditions are the same as above.

Adsorption temperature test: Take $0.2 \mathrm{~g}$ of calcium nodules through a $0.25 \mathrm{~mm}$ sieve and add $50 \mathrm{~mL}$ solutions of $\mathrm{Cu}^{2+}, \mathrm{Zn}^{2+}, \mathrm{Cd}^{2+}$, and $\mathrm{Pb}^{2+}$ at a concentration of $30 \mathrm{mg} / \mathrm{L}$. After shaking for $120 \mathrm{~min}$ at the temperature of $20^{\circ} \mathrm{C}, 30^{\circ} \mathrm{C}, 40^{\circ} \mathrm{C}, 50^{\circ} \mathrm{C}$ and $60^{\circ} \mathrm{C}$, respectively, the supernatant was centrifuged and the content of heavy metal ions was determined.

\section{Data processing}

The adsorption rate can evaluate the adsorption capacity of calcium nodules to heavy metals, and the calculation formula is: $\mathrm{Q}=(\mathrm{Ci}-\mathrm{Ce}) / \mathrm{Ci}{ }^{*} 100 \% \square$

In the formula: $\mathrm{Q}$ is the adsorption rate; $\mathrm{Ci}$ is the initial concentration of heavy metals; $\mathrm{Ce}$ is the equilibrium concentration of heavy metals added to calcareous nodules.

SPSS 18.0 software was used for data analysis, and Origin 8.0 software was used for drawing.

\section{Results And Analysis}

\subsection{Micromorphology and chemical composition of calcareous nodules}


Scanning electron microscopy (Fig. 1) shows that the calcareous nodules have a compact texture, a rough surface and a stepped shape, and the particles are smooth and have no obvious rhomboid. Some of the particles have large pores. The particles are of different sizes and shapes, mostly in the form of rods,ellipses,flakes and thin strips, etc. The thin strips and rods may be illite, the oval shape may be iron oxide, and the flakes may be kaolinite and montmorillonite(Gao B Y .et al., 2012). The adsorption of calcium nodules on heavy metal ions in water is related to its mineral type and content.In terms of chemical composition, the main component of calcareous nodules is $\mathrm{SiO}_{2}$, followed by $\mathrm{CaO}$, and then $\mathrm{Al}_{2}$ $\mathrm{O}_{3}$. The sum of the three is about $90 \%$. In contrast, $\mathrm{K}_{2} \mathrm{O}, \mathrm{NaO}, \mathrm{MgO}$ and $\mathrm{Fe}_{2} \mathrm{O}_{3}$ are easily leached out with water, and their content is relatively low (Table 1). The ratio of silicon to aluminum in calcareous nodules $\left(\mathrm{SiO}_{2} / \mathrm{Al}_{2} \mathrm{O}_{3}\right)$ reaches 2.89.Combined with the percentage of each oxide, it can be inferred that the calcareous nodules are mainly 2:1 collision type minerals such as illite and montmorillonite.The 2:1 type mineral has the characteristics of large specific surface area and fine particle size, and has a good effect on the adsorption and precipitation of heavy metal ions. Therefore, calcium nodules can be used to adsorb and remove heavy metal ions in water(Qin H F .et al., 2018)ם

Table 1

Chemical composition of calcareous nodules

\begin{tabular}{|lcccccccc|}
\hline Chemical components & $\mathrm{K}_{2} \mathrm{O}$ & $\mathrm{CaO}$ & $\mathrm{NaO}$ & $\mathrm{MgO}$ & $\mathrm{Al}_{2} \mathrm{O}_{3}$ & $\mathrm{Fe}_{2} \mathrm{O}_{3}$ & $\mathrm{SiO}_{2}$ & $\mathrm{SiO}_{2} / \mathrm{Al}_{2} \mathrm{O}_{3}$ \\
\hline Content(\%) & 2.16 & 34.57 & 1.23 & 1.78 & 14.36 & 4.34 & 41.56 & 2.89 \\
\hline
\end{tabular}

\subsection{Influence of particle size on the adsorption of heavy metal ions by calcium nodules}

The adsorption rate of heavy metal ions changes significantly with the size of the calcium nodules (Fig. 2).When the particle size is from 0.149 to $0.25 \mathrm{~mm}$, the adsorption rate of $\mathrm{Cu}^{2+}, \mathrm{Zn}^{2+}$ and $\mathrm{Pb}^{2+}$ decreases slowly.After the particle size is less than $0.25 \mathrm{~mm}$, the adsorption rate decreases greatly. The adsorption rates of $\mathrm{Cu}^{2+}, \mathrm{Zn}^{2+}$ and $\mathrm{Pb}^{2+}$ vary from $20.33-85.00 \%, 28.67-89.33 \%$ and $43.67-82.00 \%$, respectively. When the particle size of $\mathrm{Cd}^{2+}$ is from 0.149 to $0.25 \mathrm{~mm}$, the adsorption rate decreases relatively greatly, down by $14.67 \%$. After the particle size is larger than $0.25 \mathrm{~mm}$, the adsorption rate basically stabilizes. As the particle size of calcium nodules increases, the adsorption rate of heavy metal ions gradually decreases. This may be because the larger the particle size of the calcareous nodules of the same mass, the smaller the specific surface area and the relative content of layered silicate minerals such as montmorillonite and illite, thereby reducing the adsorption rate of heavy metal ions. Secondly, the difference in the content of carbonate, sulfate and hydrated oxides of iron, aluminum and magnesium in calcium nodules with different particle sizes will also affect the adsorption effect of heavy metal ions. From visual judgment, the smaller the particle size, the more turbid the solution, and the longer it takes to settle for clarification. It is better to choose calcareous nodules that pass $0.25 \mathrm{~mm}$ sieve when carrying out heavy metal ion adsorption.

\subsection{The effect of adsorption time on the adsorption of heavy metal ions by calcium nodules}


As time goes by, the adsorption rate of heavy metal ions gradually increases, but the adsorption curve is quite different (Fig. 3) $₫$ The adsorption rate of $\mathrm{Cd}^{2+}$ and $\mathrm{Pb}^{2+}$ increased significantly within the adsorption time of 1 to 60 minutes, and the increase of adsorption rate decreased significantly when the adsorption time continued to be prolonged. Compared with $\mathrm{Cd}^{2+}$ and $\mathrm{Pb}^{2+}, \mathrm{Cu}^{2+}$ and $\mathrm{Zn}^{2+}$ can reach a higher adsorption rate in a short time (within $15 \mathrm{~min}$ ). $\mathrm{Cu}^{2+}, \mathrm{Zn}^{2+}, \mathrm{Cd}^{2+}$ and $\mathrm{Pb}^{2+}$ can reach the maximum adsorption rate of $78.21 \%, 93.33 \%, 78.26 \%$ and $84.55 \%$ respectively at $30 \mathrm{~min}$. The maximum adsorption rates are $26 \%, 30.00 \%, 15.33 \%$ and $41.00 \%$, respectively. $\mathrm{Cu}^{2+}, \mathrm{Zn}^{2+}, \mathrm{Cd}^{2+}$ and $\mathrm{Pb}^{2+}$ can achieve better adsorption effects within 60 minutes. This may be caused by the combination of mineral types and contents in calcareous nodules. Due to the large concentration gradient between the calcium nodules and the heavy metal adsorption solution, the adsorption rate is relatively fast. The adsorption rate of calcium nodules to 4 kinds of heavy metal ions increased relatively smoothly after $60 \mathrm{~min}$. The adsorption time can determine the degree of adsorption of heavy metal ions to a certain extent, and affect the adsorption effect of heavy metal ions. When the time exceeds $60 \mathrm{~min}$, the adsorption rate of 4 kinds of heavy metal ions increases little with time. This study shows that the adsorption time is not the main factor affecting the adsorption rate of heavy metal ions. As long as the appropriate adsorption time is selected, a higher adsorption rate can be achieved. It is more appropriate to extend the adsorption time appropriately. Choose 120 min for comprehensive comparison.

\subsection{The effect of $\mathrm{pH}$ on the adsorption of heavy metal ions by calcium nodules}

$\mathrm{pH}$ is an important factor affecting the adsorption rate during the adsorption process, which may be related to the chemical properties of different heavy metal ions and their existence in the solution. Figure 4 shows that when $\mathrm{pH}=4$, the adsorption rate of calcium nodules on $\mathrm{Cu}^{2+}, \mathrm{Zn}^{2+}, \mathrm{Cd}^{2+}$ and $\mathrm{Pb}^{2+}$ is the smallest, which are $16.00 \%, 19.67 \%, 9.67 \%$ and $10.33 \%$, respectively. At this time, the calcium carbonate, iron, aluminum, magnesium and other oxides in the calcareous nodules begin to decompose under the action of $\mathrm{H}+$, causing damage to their structure and properties. At the same time, the concentration of $\mathrm{Ca}^{2+}, \mathrm{Fe}^{2+}, \mathrm{Al}^{3+}$ and $\mathrm{Mg}^{2+}$ in the solution is increasing continuously, forming a competitive relationship with $\mathrm{Cu}^{2+}, \mathrm{Zn}^{2+}, \mathrm{Cd}^{2+}$ and $\mathrm{Pb}^{2+}$ in the solution, which in turn affects the adsorption of heavy metal ions. With the gradual increase of $\mathrm{pH}$, the adsorption rate of $\mathrm{Cd}^{2+}$ increases firstly and then slowly, and the maximum adsorption rate is $30.33 \%(\mathrm{pH}=8)$. The adsorption rates of $\mathrm{Zn}^{2+}$ and $\mathrm{Pb}^{2+}$ first increase and then decrease, the maximum adsorption rates are $40.67 \%(\mathrm{pH}=6)$ and $49.67 \%(\mathrm{pH}=7)$, respectively. When the $\mathrm{pH}$ is 5 , the adsorption rate of $\mathrm{Cu}^{2+}$ reaches the maximum, when the $\mathrm{pH}>5$, the adsorption rate is significantly reduced, and when the $\mathrm{pH}=6 \otimes 8$, the adsorption rate is basically stable.

Studies have shown that under different $\mathrm{pH}$, the existence of metal ions is different. The $\mathrm{Cd}^{2+}$ adsorption process is mainly complex and potential adsorption(Li L I .et al., 2012), so the higher the $\mathrm{pH}$, the more helpful the $\mathrm{Cd}^{2+}$ adsorption. $\mathrm{Cu}^{2+}, \mathrm{Zn}^{2+}$ and $\mathrm{Pb}^{2+}$ are mainly adsorbed by precipitation. With the increase of $\mathrm{pH}$, heavy metal ions are gradually converted into hydroxide complex ions. Among them, $\mathrm{Cu}^{2+}$ begins to precipitate after $\mathrm{pH}=5$, and $\mathrm{Zn}^{2+}$ begins to precipitate after $\mathrm{pH}=6$. After $\mathrm{pH}=7, \mathrm{~Pb}^{2+}$ began to 
precipitate, so with the increase of $\mathrm{pH}$, the changes in the adsorption rates of the four heavy metal ions were inconsistent (Tsao TM .et al., 2012;Zhu H .et al., 2006;Zhang Z Y .et al., 2017;Chou YM .et al., 2014).

\subsection{Effect of the amount of adsorbent on the adsorption of heavy metal ions by calcium nodules}

The adsorption rate of calcium nodules on $\mathrm{Cu}^{2+}, \mathrm{Zn}^{2+}, \mathrm{Cd}^{2+}$ and $\mathrm{Pb}^{2+}$ in the solution gradually increases with the increase in the amount of calcium nodules (Fig. 5). When the dosage is increased to $0.6 \mathrm{~g}$, the adsorption rate of the calcium nodules on the 4 kinds of heavy metal ions gradually slows down. The amount of calcareous nodules has a weak effect on the adsorption rate of $\mathrm{Cd}^{2+}$, with a range of only $16.00-27.67 \%$, and the most obvious impact on $\mathrm{Pb}^{2+}$, with a range of change from $43.00-76.00 \%$, which is nearly doubled. The order of the adsorption effect of calcareous nodules on the four heavy metal ions is $\mathrm{Pb}^{2+}>\mathrm{Zn}^{2+}>\mathrm{Cu}^{2+}>\mathrm{Cd}^{2+}$, in which the maximum adsorption rates of $\mathrm{Cu}^{2+}$ and $\mathrm{Cd}^{2+}$ are both lower than $40 \%$, and the adsorption rate of $\mathrm{Pb}^{2+}$ is as high as $80 \%$. This may be related to the difference in electronegativity of $\mathrm{Cu}^{2+}, \mathrm{Zn}^{2+}, \mathrm{Cd}^{2+}$ and $\mathrm{Pb}^{2+}$ (Tao, Ye et al., 2017). Although the high dosage of calcium nodules is beneficial to increase the adsorption rate of heavy metal ions, it will cause turbid water quality and poor visual effect. Considering the adsorption effect and visual senses, $0.6 \mathrm{~g}$ is more suitable for practical applications.

\subsection{Influence of the initial concentration of heavy metals on the adsorption of heavy metal ions by calcium nodules}

With the increase of the initial concentration of heavy metal ions, the adsorption rate of calcium nodules on $\mathrm{Cu}^{2+}, \mathrm{Zn}^{2+}$ and $\mathrm{Cd}^{2+}$ showed a significant downward trend, while $\mathrm{Pb}^{2+}$ first increased and then decreased (Fig. 6). This may be because the initial concentration is low, there are many adsorption sites on the surface of calcareous nodules, and the concentration of heavy metal ions in the solution is different, so the adsorption rate is large. As the initial concentration of heavy metals increases, the adsorption sites are saturated, resulting in a decrease in the adsorption rate. The initial concentration of heavy metal ions has much greater influence on the adsorption rate of $\mathrm{Cu}^{2+}, \mathrm{Cd}^{2+}$ and $\mathrm{Pb}^{2+}$ than $\mathrm{Zn}^{2+}$. In the range of $100 \mathrm{mg} / \mathrm{L}$, the adsorption rate of $\mathrm{Zn}^{2+}$ changed the most slowly, only decreasing by $27.80 \%$, while the adsorption rate of $\mathrm{Cu}^{2+}, \mathrm{Cd}^{2+}$ and $\mathrm{Pb}^{2+}$ decreased greatly, decreasing by $84.60 \%, 70.80 \%$ and $69.00 \%$ respectively. The adsorption rate of 4 kinds of heavy metal ions is better at lower concentration, and worse at higher concentration. As far as $\mathrm{Pb}^{2+}$ is concerned, in the range of $30 \mathrm{mg} / \mathrm{L}$, although the adsorption rate has a downward trend, it still remains above $40 \%$. For $\mathrm{Cu}^{2+}$, the change trend is similar, the adsorption rate remains above $40 \%$ in the range of $20 \mathrm{mg} / \mathrm{L}$, and the adsorption rate remains above $30 \%$ in the range of $30 \mathrm{mg} / \mathrm{L}$. The adsorption rate of $\mathrm{Cd}^{2+}$ and $\mathrm{Zn}^{2+}$ is lower than $30 \%$ in the range of 20 $\mathrm{mg} / \mathrm{L}$, and the adsorption rate reaches the maximum at $10 \mathrm{mg} / \mathrm{L}, 74.00 \%$ and $38.00 \%$ respectively. Comprehensive consideration of calcium nodules is more suitable for treating low-concentration wastewater.

\subsection{The effect of temperature on the adsorption of heavy metal ions by calcium nodules}


With the increase of temperature, the adsorption rate of calcium nodules on $\mathrm{Cu}^{2+}, \mathrm{Zn}^{2+}, \mathrm{Cd}^{2+}$ and $\mathrm{Pb}^{2+}$ all increase (Fig. 7), indicating that heating is helpful to the advancement of the adsorption process. When the temperature is in the range of $20-40{ }^{\circ} \mathrm{C}$, the adsorption rate increases slowly, and when the temperature reaches $40^{\circ} \mathrm{C}$, the adsorption rate increases sharply. This may be because the higher the temperature, the higher the adsorption and exchange rate of heavy metal ions. The order of the influence of temperature change on the adsorption of heavy metal ions by calcium nodules is $\mathrm{Pb}^{2+} \square \mathrm{Cu}^{2+} \square \mathrm{Zn}^{2+} \square \mathrm{Cd}^{2}+$. Among them, in the range of $20-40{ }^{\circ} \mathrm{C}$, the change of temperature has a weak effect on the adsorption rate of $\mathrm{Pb}^{2+}$, and the adsorption rate only increases by $5.67 \%$. When the temperature reaches $60{ }^{\circ} \mathrm{C}$, the adsorption rate increases by $46.00 \%$. The adsorption rate of $\mathrm{Cu}^{2+}, \mathrm{Zn}^{2+}$ and $\mathrm{Cd}^{2+}$ increases linearly with the increase of temperature. When the temperature reaches $60{ }^{\circ} \mathrm{C}$, the adsorption rate increases by $55.67 \%, 66.33 \%$ and $73.67 \%$, respectively. When the temperature is $50^{\circ} \mathrm{C}$, the adsorption rates of $\mathrm{Cu}^{2+}, \mathrm{Zn}^{2+}, \mathrm{Cd}^{2+}$ and $\mathrm{Pb}^{2+}$ can reach $79.00 \%, 76.00 \%, 72.00 \%$ and $70 \%$ of their maximum adsorption rates respectively. Although the increase in temperature can improve the adsorption effect of heavy metal ions, too high temperature is not conducive to the survival of aerobic microorganisms in the water body, and will affect the decomposition of other pollutants by the microorganisms in the water body. Combined with the actual situation of wastewater treatment, it is more appropriate to choose $50^{\circ} \mathrm{C}$.

\section{Discussion}

Because heavy metals have significant toxicity to humans, animals, plants and microorganisms and cannot be degraded by microorganisms, heavy metal wastewater has become a major global environmental problem(Tofighy M A .et al., 2011).Compared with other methods, the adsorption method has the characteristics of simple operation, high efficiency and low cost, and has been widely used in the treatment of heavy metal wastewater(Li L I .et al., 2012). The adsorbent is the core factor of the adsorption method, and its performance determines the quality of the separation effect and the level of separation efficiency.At present, adsorbents used for heavy metal treatment can be divided into natural adsorbents, biological adsorbents and synthetic adsorbents according to their source and chemical structure(Peng W .et al., 2017).

Loess-calcium binding is one of the natural adsorbents, and there are few studies on this adsorbent at present. However, some scholars have conducted research on the adsorption effect of other adsorbents on water heavy metals. The results show that $\mathrm{PH}$, time, Adsorbent dosage, temperature and initial concentration of heavy metals are important factors affecting the adsorption effect of different adsorbents, which are consistent with our research results(Peng W .et al., 2017;D. Gu .et al., 2015;Zhang Z .et al., 2015;Wang YY .et al., 2018;Li L IY .et al., 2012;Liu J .et al., 2018;Hu H .et al., 2012). For example: Sheikhhosseini A et al. studied Competitive sorption of nickel, cadmium, zinc and copper on palygorskite and sepiolite silicate clay minerals(Sheikhhosseini A .et al., 2013). The research results show that palygorskite and sepiolite can effectively remove Cu from the solution regardless of the presence of other metals. Zou J et al. used corn stalks to prepare biochar, conducted experiments on the adsorption of 
heavy metals $\mathrm{Cd}^{2+}$ and $\mathrm{Pb}^{2+}$, and analyzed the adsorption capacity and adsorption efficiency of biochar to adsorb heavy metals(Zou J .et al., 2018). The results show that the optimal adsorption condition for $\mathrm{Cd}^{2+}$ is that the $\mathrm{pH}$ is 5 and the adsorption equilibrium is $120 \mathrm{~min}$. The optimal adsorption condition for $\mathrm{Pb} 2+$ is that the $\mathrm{p} \mathrm{H}$ is 1 , and the adsorption equilibrium is $60 \mathrm{~min}$. This is basically consistent with the results of the study on the effect of adsorption time on calcium binding and adsorption of heavy metal ions in this article. LI Li et al. studied the adsorption mechanism of corn stover biochar on $\mathrm{Cd}(\mathbb{\nabla})(\mathrm{Li} \mathrm{L}$ I .et al., 2012). The results showed that with the increase of $\mathrm{PH}$, its adsorption rate continued to increase; our research also showed that with the increase of $\mathrm{PH}$, its adsorption rate continued to increase. However, when reaching a certain value, the adsorption rate of different heavy metals will increase slowly or decrease. Peng W's research shows that the optimal solution $\mathrm{pH}$ for the adsorption of various heavy metal ions may be different due to their differences in the metal electronegativity, the standard reduction potential of the heavy metal ions and the first stability constant of the associated metal hydroxide(Peng W .et al., 2017). At the same time, As far as the amount of adsorbent is concerned, an appropriate amount of adsorbent can achieve the best adsorption effect, not as much as possible. In terms of time, as time increases, the adsorption effect increases, but the growth is slow after a period of time, just choose an appropriate adsorption time. In terms of temperature, as the temperature increases, the adsorption effect increases, but the most suitable temperature for different heavy metals is different. The above research conclusions are basically consistent with our research results.

\section{Conclusion}

Different adsorption conditions have different effects on the adsorption of heavy metal ions by calcium nodules. The particle size has a greater influence on the adsorption of $\mathrm{Cu}^{2+}, \mathrm{Zn}^{2+}$ and $\mathrm{Pb}^{2+}$ by calcareous nodules. As the particle size increases, the adsorption rate gradually decreases, but it has no significant effect on the adsorption of $\mathrm{Cd}^{2+}$. With the increase of the adsorption time and the amount of adsorbent, the adsorption rate of $\mathrm{Cu}^{2+}, \mathrm{Zn}^{2+}, \mathrm{Cd}^{2+}$ and $\mathrm{Pb}^{2+}$ increases first abruptly and then gradually increases, and the adsorption curves are similar. As the temperature rises, the adsorption rate first increases gently and then increases abruptly. With the increase of the initial concentration of heavy metal ions, the adsorption rate of $\mathrm{Cu}^{2+}, \mathrm{Zn}^{2+}$ and $\mathrm{Cd}^{2+}$ gradually decreased, while the adsorption rate of $\mathrm{Pb}^{2+}$ increased first and then decreased. As the $\mathrm{pH}$ increases, the adsorption rate of $\mathrm{Cd}^{2+}$ increases first and then slowly increases, while the adsorption rate of $\mathrm{Cu}^{2+}, \mathrm{Zn}^{2+}$ and $\mathrm{Pb}^{2+}$ first increases and then decreases.

The adsorption capacity of calcium nodules for 4 kinds of heavy metal ions is in the order of $\mathrm{Pb}^{2+}>\mathrm{Zn}^{2+}>\mathrm{Cu}^{2+}>\mathrm{Cd}^{2+}$. Calcareous nodules can achieve better adsorption of $\mathrm{Pb}^{2+}, \mathrm{Zn}^{2+}, \mathrm{Cu}^{2+}$ and $\mathrm{Cd}^{2+}$ when the particle size is $0.25 \mathrm{~mm}$, the adsorption time is $120 \mathrm{~min}$, and the dosage is $0.6 \mathrm{~g}$. The adsorption rates are $63.33 \%, 42.00 \%, 31.00 \%$ and $22.67 \%$ respectively, Respectively can reach $83.33 \%$, $77.78 \%, 73.81 \%$ and $81.93 \%$ of its maximum adsorption rate. $\mathrm{pH}$ and temperature have a great influence on the adsorption of heavy metal ions by calcium nodules. The appropriate $\mathrm{pH}$ and temperature should be selected for different types of metal ions. Among them, the optimal adsorption $\mathrm{pH}$ of $\mathrm{Pb}^{2+}, \mathrm{Zn}^{2+}, \mathrm{Cu}^{2+}$ and $\mathrm{Cd}^{2+}$ are $7,6,5,8$, and the optimal temperature is $50{ }^{\circ} \mathrm{C}$. 


\section{Declarations}

Funding: The study is supported by the Fund Project of Shaanxi Key Laboratory of Land Consolidation (2019-ZD05).

\section{Author contributions}

Conceptualization: Qi Li, Yanan Li

Data curation: Qi Li

Formal analysis: Xiaoxiao Shu, Yanan Li

\section{References}

[1] Chou YM, Song SR, Tsao MT, et al. Identification and tectonic implications of nano-particle quartz (< $50 \mathrm{~nm}$ ) by synchrotron X-ray diffraction in the Chelungpu fault gouge, Taiwan. Tectonophysics, 2014, 619-620, 21: 36-43.

[2] D. Gu, J.B. Fein, Colloids Surf. A Physicochem. Eng. Asp. 481 (2015) 319.

[3] Gong T , Zhu Y . Spatial pattern of caliche nodule in surface soil of the hillslopes in Liudaogou catchment in the wind-water erosion crisscross zone of the Loess Plateau[J]. Science of Soil and Water Conservation, 2016.

[4] He H P , Guo J G , Zhu J X. An experimental study of adsorption capacity of montmorillonite, kaolinite and illite for heavy metals[J]. Acta Mineralogica et Petrologica, 2001, 20(4):573-578.

[5] Gong Tiexiong. Study on the distribution of calcareous nodules and their water characteristics on slopes in loess area[D]. University of Chinese Academy of Sciences, 2017.

[6] Gao B Y , Qiu T , Rong-Huab L I, et al. Investigation of heavy metal ions adsorption ability by thiolmodified corn stalk powder[J]. Journal of Northwest A \& F University, 2012, 40(3):185-190.

[7] Hu H , Liu G . The Trend of Heavy Metal Wastewater Treatment by Adsorption Method[C]// International Conference on Remote Sensing. 2012.

[8] Li LI , Yu-Chao L U , Liu Y , et al. Adsorption Mechanisms of Cadmium( $『$ )on Biochars Derived from Corn Straw. Journal of Agro-Environment Science, 2012.

[9] Li Chang'an,Wu Jinping,Cao Jiangxiong.The morphology of loess calcareous nodules in northwest Hebei and their genesis dynamic characteristics and stratigraphic environmental significance[J].Earth Science,1995(05):511-514. 
[10] Liu J , Liu L , Xue J, et al. Research progress on treatment of heavy metal wastewater by adsorption. Environmental Chemistry, 2018.

[11] Peng $W$, Li H, Liu Y , et al. A review on heavy metal ions adsorption from water by graphene oxide and its composites[J]. Journal of Molecular Liquids, 2017, 230:496-504.

[12] Qin H F , Zhang W M . Adsorption of Lead and Cadmium by Hydroxyapatite Coated Quartz Sands. Science Technology and Engineering, 2018.

[13] Sheikhhosseini A, Shirvani M, Shariatmadari H. Competitive sorption of nickel, cadmium, zinc and copper on palygorskite and sepiolite silicate clay minerals[J]. Geoderma, 2013, 192(1): 249-253.

[14] Tofighy M A , Mohammadi T . Adsorption of divalent heavy metal ions from water using carbon nanotube sheets[J]. Journal of Hazardous Materials, 2011, 185(1):140-147.

[15] Teng Zhihong, Liu Rongmo, Chen Ling, et al. Research on calcareous nodules in the loess strata of China[J]. Chinese Science Bulletin, 1990(13): 1008-1011.

[16] Tsao TM, Chen YM, Sheu HS, et al. Red soil chemistry and mineralogy reflect uniform weathering environments in fluvial sediments, Taiwan[J]. Journal Soils Sediments, 2012, 12: 1054-1065.

[17] Tao, Ye, Li, et al. [Evaluation of the Combined Removal of Heavy Metals by Saponin and Citric Acid from Municipal Sewage Sludges and Metal Stability Features].[J]. Huanjing Kexue, 2017..

[18] Wang Shouyu. Study on the Petrological Characteristics of N2 Red Clay in Northern Shanxi[D]. China University of Mining and Technology, 2017.

[19] Wang YY, Liu YX, Lu HH, et al. Competitive adsorption of $\mathrm{Pb}(\mathbb{\nabla}), \mathrm{Cu}(\mathbb{\nabla})$, and $\mathrm{Zn}(\mathbb{\nabla})$ ions onto hydroxyapatite-biochar nano composite in aqueous solutions[J]. Journal of Solid State Chemistry, 2018,261:53-61.

[20] Yang L G , Qiao D Y , Peng-Yu H U , et al. Determination of thirteen elements in soil by inductively coupled plasma mass spectrometry with automatic digestion instrument. Soil and Fertilizer Sciences in China, 2019.

[21] Zehua J I, Xiaofu W U , Yun L I, et al. Kinetic adsorption and change in chemical potential of heavy metal ions in aqueous solutions. Environmental Chemistry, 2015.

[22] Zhu H, Chen W, Li Y, et al. Aggregation kinetics of natural soil nanoparticles in different electrolytes[J]. European journal of soil science, 2014, 65, 206-217.

[23] Zhang Z Y, Huang L, Liu F, et al. The properties of clay minerals in soil particles from two Ultisols, China[J]. clays and clay minerals, 2017, 65: 273-285. 
[24] Zhang Z , Bao L I , Liang R. Comparison of sediment heavy metal fractions at estuary and center of Nanyang Zone from Nansi Lake,China[J]. Huanjing Kexue Xuebao / Acta Scientiae Circumstantiae, 2015, 35(5):1408-1416.

[25] Zou J , D Sun, Zhao J , et al. Adsorption of Heavy Metal Cd,Pb by Maize Straw Biochar. Journal of Beihua University(Natural Science), 2018.

\section{Figures}
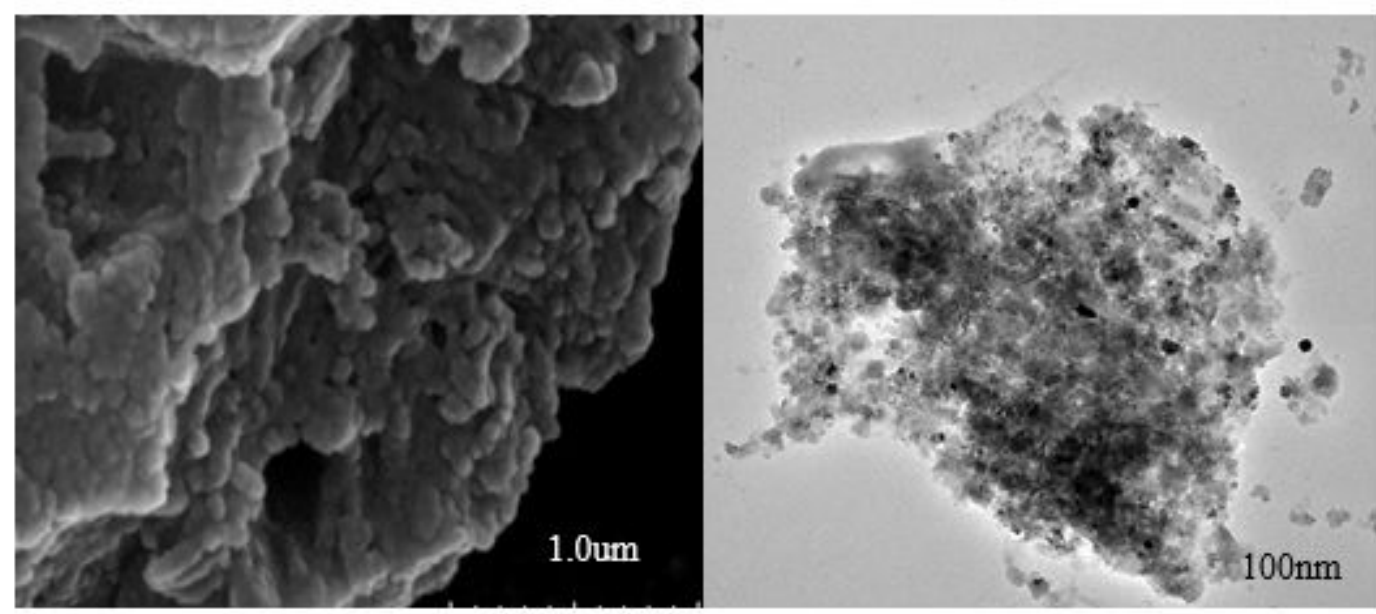

\section{Figure 1}

Scanning electron micrograph of calcareous nodules

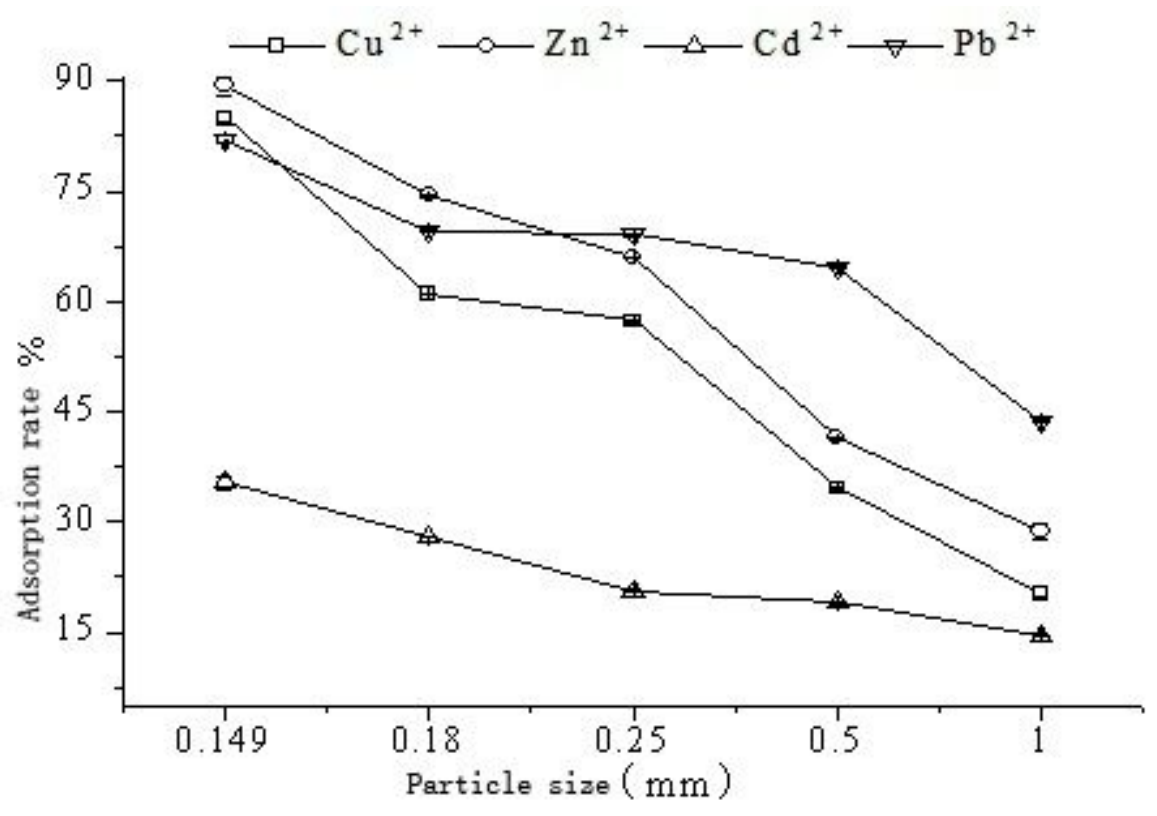

\section{Figure 2}

The adsorption effect of different particle size calcium nodules on $\mathrm{Cu} 2+, \mathrm{Zn} 2+, \mathrm{Cd} 2+$ and $\mathrm{Pb} 2+$ in solution 


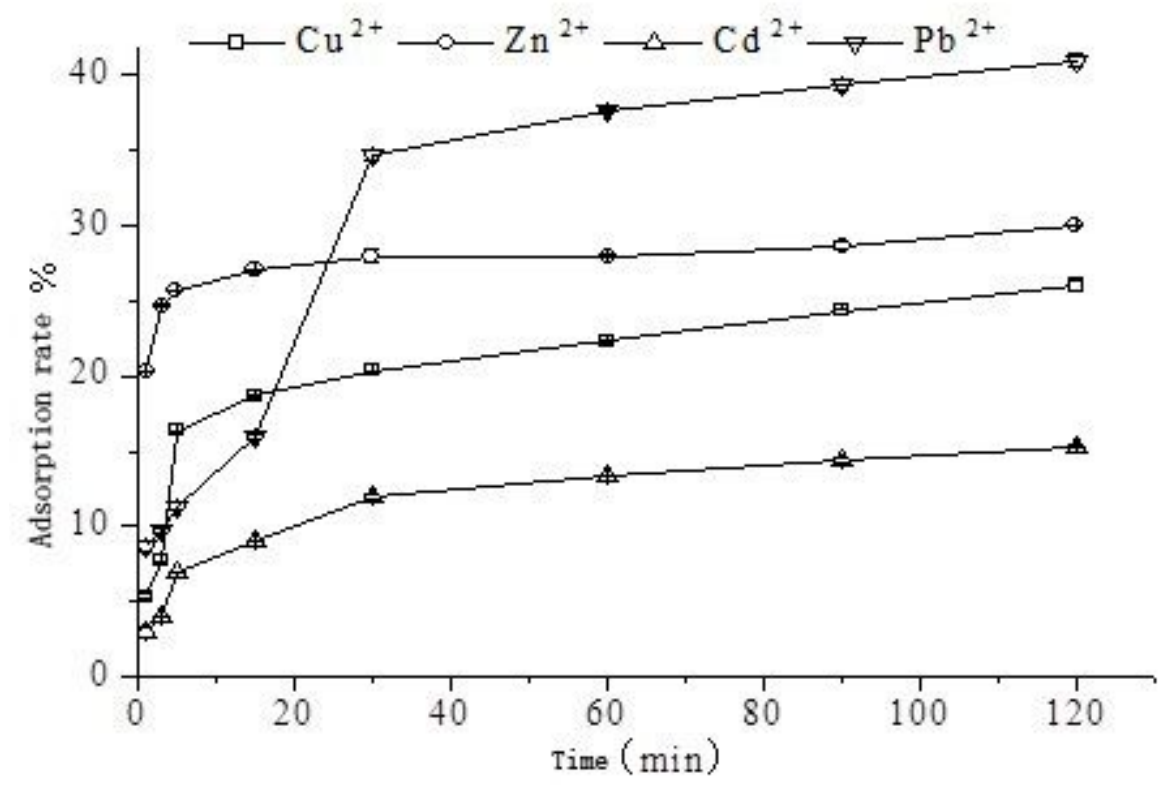

Figure 3

The adsorption effect of adsorption time on $\mathrm{Cu} 2+, \mathrm{Zn} 2+, \mathrm{Cd} 2+$ and $\mathrm{Pb} 2+$ in solution

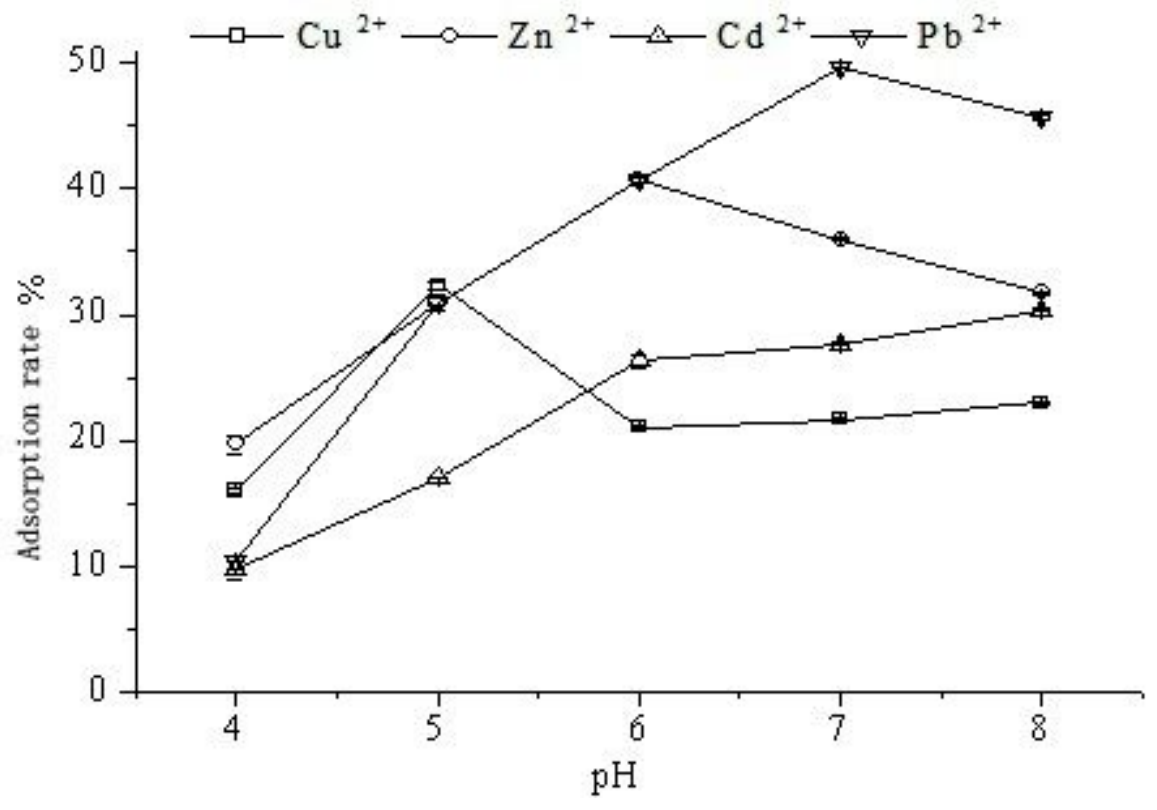

Figure 4

The adsorption effect of $\mathrm{pH}$ on $\mathrm{Cu} 2+, \mathrm{Zn} 2+, \mathrm{Cd} 2+$ and $\mathrm{Pb} 2+$ in solution 


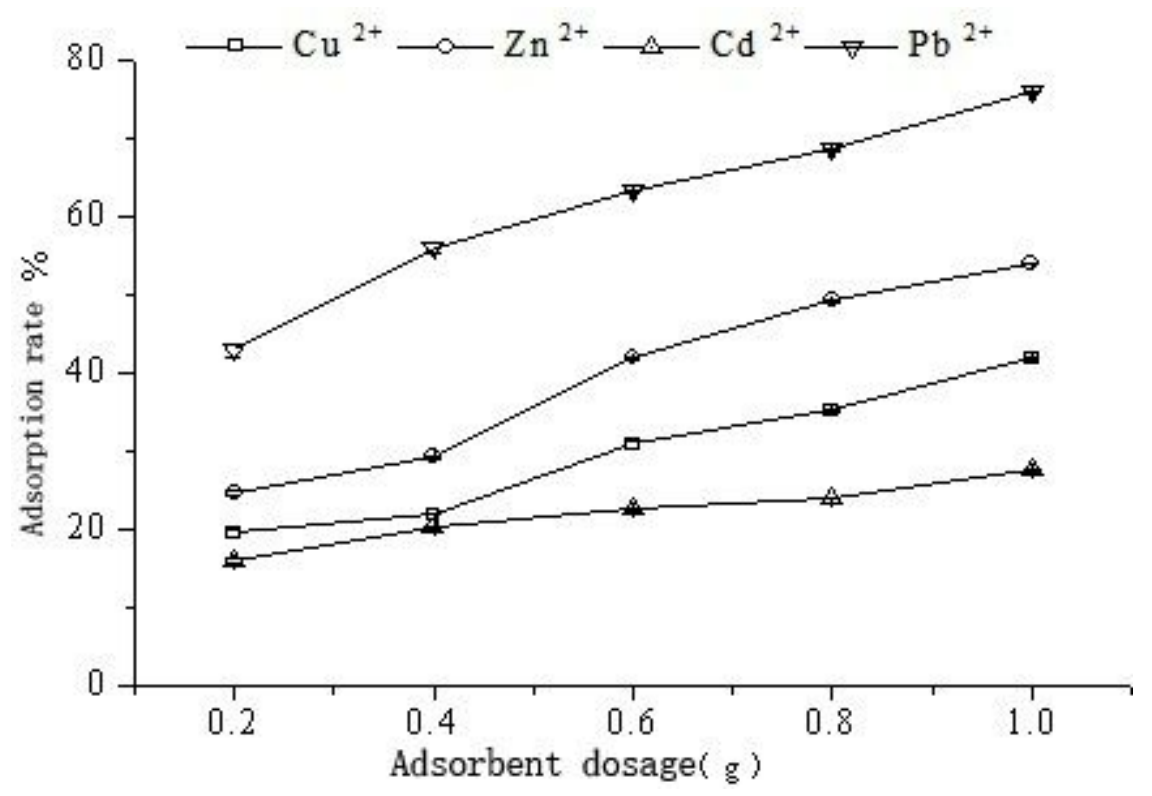

Figure 5

The adsorption effect of the amount of adsorbent on $\mathrm{Cu} 2+, \mathrm{Zn} 2+, \mathrm{Cd} 2+$ and $\mathrm{Pb} 2+$ in the solution

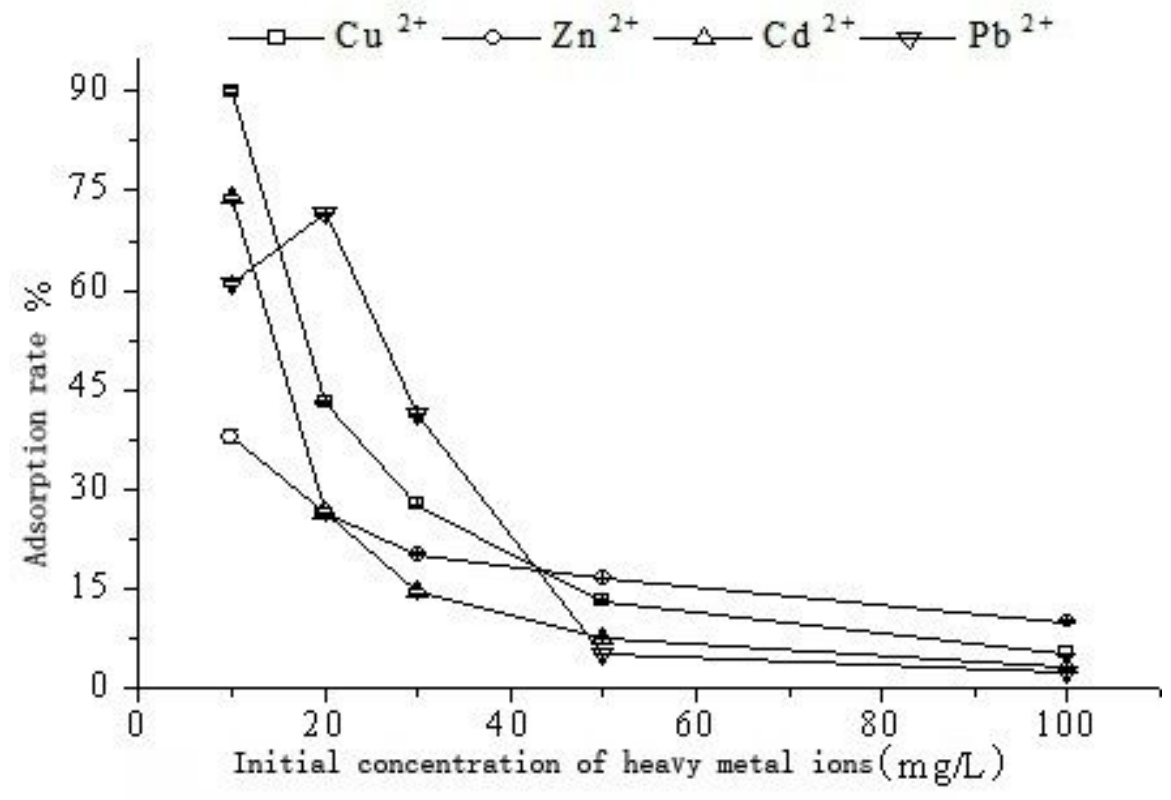

Figure 6

The adsorption effect of the initial concentration of heavy metal ions on $\mathrm{Cu} 2+, \mathrm{Zn} 2+, \mathrm{Cd} 2+$ and $\mathrm{Pb} 2+$ in the solution 


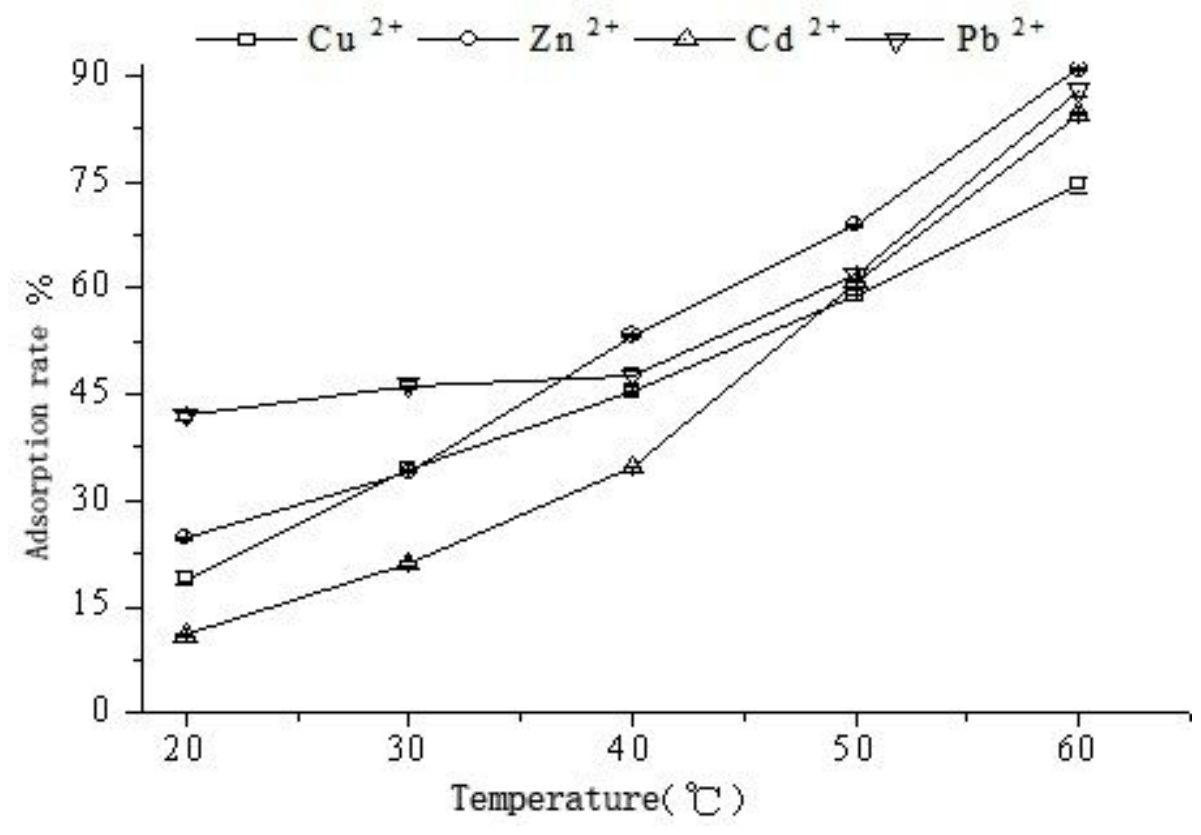

Figure 7

Adsorption effect of temperature on $\mathrm{Cu} 2+, \mathrm{Zn} 2+, \mathrm{Cd} 2+$ and $\mathrm{Pb} 2+$ in solution 